\title{
Working and Reference Memory in Rats in the Three-Panel Runway Task Following Dorsal Hippocampal Lesions
}

\author{
Iwao Kitajima, Tsuneyuki Yamamoto*, Masuo Ohno and Showa Ueki \\ Department of Pharmacology, Faculty of Pharmaceutical Sciences, \\ Kyushu University 62. Fukuoka 812, Japan \\ Received September 17, 1991 Accepted November 22, 1991
}

\begin{abstract}
Using a three-panel runway task, the influence of dorsal hippocampal lesions on working and reference memory in rats was investigated. Despite 20 postoperative training sessions, rats with hippocampal lesions were unable to perform the working memory task. In the acquisition process of the reference memory task, however, there was no significant difference between hippocampal- and sham-lesioned rats. On the other hand, rats trained preoperatively with a working memory procedure, and then subjected to hippocampal lesions, showed more errors (pushes made on the two incorrect panels of the three panel-gates located at four choice points) than did sham-lesioned rats. The increase in working errors induced by hippocampal lesions was not reduced during 10 subsequent re-training sessions. Hippocampal lesions had no effect on retention of the reference memory performance. The increase in working errors in hippocampal-lesioned rats was significantly reduced by treatment with the cholinestcrase inhibitor physostigmine at $0.1 \mathrm{mg} / \mathrm{kg}$ and the cholinergic activating drug minaprine at $10 \mathrm{mg} / \mathrm{kg}$. These findings suggest that lesions of the dorsal hippocampus selectively impair the ability to carry out the working memory task whether rats are trained preoperatively or postoperatively, and that the working memory loss in hippocampal-lesioned rats is mediated by lowering of the cholinergic function.
\end{abstract}

The hippocampus is implicated as a brain structure necessary for normal memory functions in animals and humans. It has been shown that lesions of the septo-hippocampal system in rats cause profound memory deficits, as assessed in a radial maze task $(1,2)$. Hippocampal lesions also impair the place learning of rats in the water maze task (3). The mnemonic interpretation of hippocampal function is supported by the appearance of a severe amnesic syndrome in patient H.M. fol-

\footnotetext{
* To whom all correspondence should be addressed.
}

lowing bilateral removal of the temporal lobe (4) and patient R.B. following a lesion limited to the hippocampus (5). On the other hand, neuronal loss and a great number of neurofibrillary tangles and senile plaques have been found in the hippocampus of patients with Alzheimer's disease (AD) and senile dementia of the Alzheimer type (SDAT) $(6,7)$. In the hippocampal formation, there are also marked reductions in the activity of choline acetyltransferase, the enzyme that synthesizes acetylcholine, in these pathological states $(8,9)$. In light of the role of the hippocampus in mem- 
ory, these changes are likely to contribute to the memory deficits seen in AD and SDAT patients.

We previously reported a new method for the study of learning and memory in rats, using a three-panel runway apparatus $(10,11)$. In the present study, we investigated the acquisition and retention of the runway performance of rats with dorsal hippocampal lesions based on working and reference memory procedures. In addition, the effects of cholinergic stimulant drugs on the memory deficit induced by dorsal hippocampal lesions were examined.

\section{MATERIALS AND METHODS}

\section{Subjects}

Eight- to ten-week-old male rats of the Wistar strain (Nippon SLC) were used in a threepanel runway task. Initially, their free-feeding weights were $230-250 \mathrm{~g}$, but at the start of the experiment, they were maintained at approximately $80 \%$ of this level. The rats were housed in groups of four per cage with water freely available. A rat was given three food chops (about $15 \mathrm{~g}$ ) per day. Room temperature was kept at $23 \pm 2^{\circ} \mathrm{C}$ with a $12-\mathrm{hr}$ light-dark cycle (light period: $07: 00-19: 00$ ) throughout the experimental period.

\section{Three-panel runway task}

Working and reference memory werc assessed by a three-panel runway apparatus $(10$. 11). The apparatus $(175 \times 36 \times 25 \mathrm{~cm}$, length $\times$ width $\times$ height) is composed of a start box, a goal box, and four consecutive intervening choice points. Each choice point consists of a gate with three panels $(12 \times 25 \mathrm{~cm}$, width $\times$ height). The rats are prohibited from passing through two of the three panels in the gatc by front stoppers and are also prohibited from returning either to the start box or to a previous choice point by rear stoppers affixed to each of the panels in all gates. When the rats reach the goal box, they can obtain two food pellets (about $50 \mathrm{mg}$ each, Muromachi Kikai).

Initially, all front stoppers were removed so that at each choice point a rat could pass through any one of the three panel-gates. The rats were made to run the task repeatedly until the time elapsed from leaving the start box to reaching the goal box fell consistenly below $20 \mathrm{sec}$. Once rats reached this state, they were made to run the task under the condition that the front stopper of only one of the three panel-gates (the correct panel-gate) was removed at each choice point.

In the working memory task, six consecutive trials were performed each day at 2-min intervals (one session). The locations of the correct panel-gates were held constant within a session, but were changed from one session to the next. Thus, twelve patterns of correct panel-gate locations were used in this experiment, as described previously $(10,11)$. In the reference memory task, three consecutive trials were given each day at 2-min intervals (one session). The locations of the correct panel-gates were held constant both within a session and in succeeding sessions. The number of times an animal pushed an incorrect panel-gate (errors) and the time required for the animal to take food pellets (latency) were recorded for each rat in each trial of a session. The criteria for learning were less than 8 errors summed from the second to sixth trial in the working memory task and less than 1 error per trial in the reference memory task for each of three consecutive sessions.

\section{Hippocampal lesions}

Rats under pentobarbital anesthesia were fixed in a stereotaxic instrument. Lesions of the dorsal hippocampus were produced with a lesion generator (Muromachi Kikai, RFG-4A) in which the temperature of the electrode tip could be monitored. The electrode $(0.25 \mathrm{~mm}$ in diameter, $1.0-\mathrm{mm}$ exposed tip) was inserted into the dorsal hippocampus (anterior: -3.3 $\mathrm{mm}$ from the bregma, lateral: $2.6 \mathrm{~mm}$ from the midline, horizontal: $2.8 \mathrm{~mm}$ from the dura) according to the rat brain atlas of Paxinos and Watson (12). The bilateral hippocampal lesions were induced by an increase in the tissue temperature to $70^{\circ} \mathrm{C}$ within $15 \mathrm{sec}$, with maintenance of this temperature for another 
$30 \mathrm{scc}$. The sham-lesioned rats were treated using the same procedure, but without increasing the tissuc temperature after insertion of the electrode.

\section{Experimental procedure}

The experiment was divided into two sections to investigate the effects of dorsal hippocampal lesions on two different processes of learning and memory in the threc-panel runway task.

Experiment 1: This experiment was designed to examine if hippocampal lesions impair the acquisition process in the working and reference memory tasks. First, rats received hippocampal lesions. Five days after surgery, the hippocampal lesioned rats were trained to take food pellets placed in the goal box with removal of all front stoppers of three panelgates. From the following day, the rats were made to run the task on the condition that they could pass through only one of the three panel-gates at all choice points.

Experiment 2: Before receiving hippocampal lesions, rats were trained in the working and reference procedure used in the three-panel runway task. After the animals achieved the criterion of learning, they were subjected to the hippocampal lesions. They were allowed 5 days to recover from surgery before being given the runway test. Thereafter, testing was conducted once daily for 10 days. In other groups of hippocampal lesioned rats, the effects of some drugs on the memory impairment were examined 5 days after surgery. In addition to experiments with hippocampal lesioned rats, animals that achieved the criterion of the reference memory task were subjected to the scopolamine test.

\section{Drugs}

The drugs used in this study were physostigmine salicylate (Sigma), minaprine [3-(2-morpholino-cthylamino)-4-methyl-6-phenyl-pyridazine dihydrochloride, Sanofi], $S$-adenosyl-Lmethionine sulfate tosylate (Fuji Chemical Industry) and (-)scopolamine hydrobromide (Sigma). Physostigmine, minaprine and scopo- lamine were dissolved in distilled water. $S$ Adenosyl-L-methionine was dissolved in phosphate buffer solution, and the $\mathrm{pH}$ was adjusted to $\mathrm{pH} 4.0-6.0$ with $\mathrm{NaOH}$ solution. Physostigmine $(0.1 \mathrm{mg} / \mathrm{kg})$ and minaprine $(10$ $\mathrm{mg} / \mathrm{kg}$ ) were administered p.o. $1 \mathrm{hr}$ before the runway test. $S$-Adenosyl-L-methionine (180 $\mathrm{mg} / \mathrm{kg}$ ) was injected i.p. $50 \mathrm{~min}$ before testing. Rats were injected i.p. with scopolamine $(0.56 \mathrm{mg} / \mathrm{kg}) 20 \mathrm{~min}$ before the test session. The doses for the drugs were expressed in terms of the salt and were adopted as an optimal dose determincd on the basis of our previous behavioral studies $(11,13,14)$.

\section{Histology}

After completion of testing, the rats were anesthetized with ether, and the brain was perfused with $10 \%$ formalin solution through the left cardiac ventricle. After the brain was removed, sectioned slices at $50 \mu \mathrm{m}$ thickness were stained with cresyl violet. The site and extent of the hippocampal lesions were verified histologically. The extent of the minimum and maximum lesions of the dorsal hippocampus are illustrated in Fig. 1. The lesions produced damage ranging from 2.3 to $4.3 \mathrm{~mm}$ posterior to the bregma.

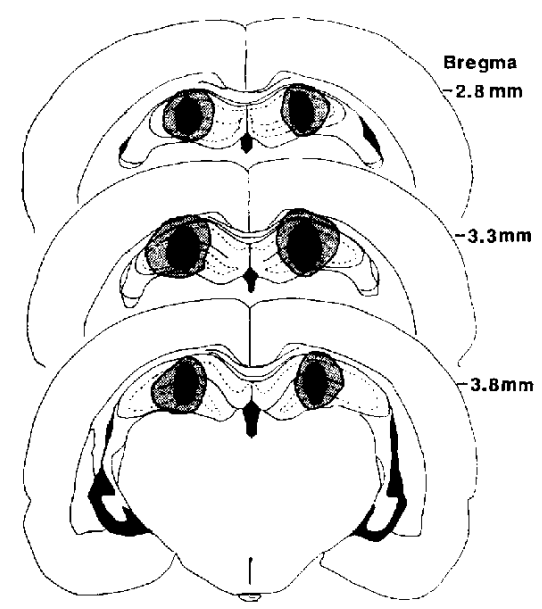

Fig. 1. Schematic drawing of the minimum (black area) and maximum (black + stippled area) extent of dorsal hippocampal lesions. Taken from the atlas of Paxinos and Watson (12). 


\section{Statistical analysis}

In the working memory task, the number of errors and latency summed from the second to sixth trial of a session were important for evaluating the ability of rats to remember new correct panel-gate locations, and thus presented separately from those of the first trial. In the reference memory task, both items in the first of three trials were presented because they were important for evaluating the holding of the constant location of correct panel-gates.
The significance of the differences between groups was analyzed using the Mann-Whitney $U$-test.

\section{RESULTS}

\section{Experiment 1}

In the working memory task, the total number of errors from the second to sixth trial decreased markedly with repetition of training in the sham-lesioned rats (Fig. 2, upper panels),
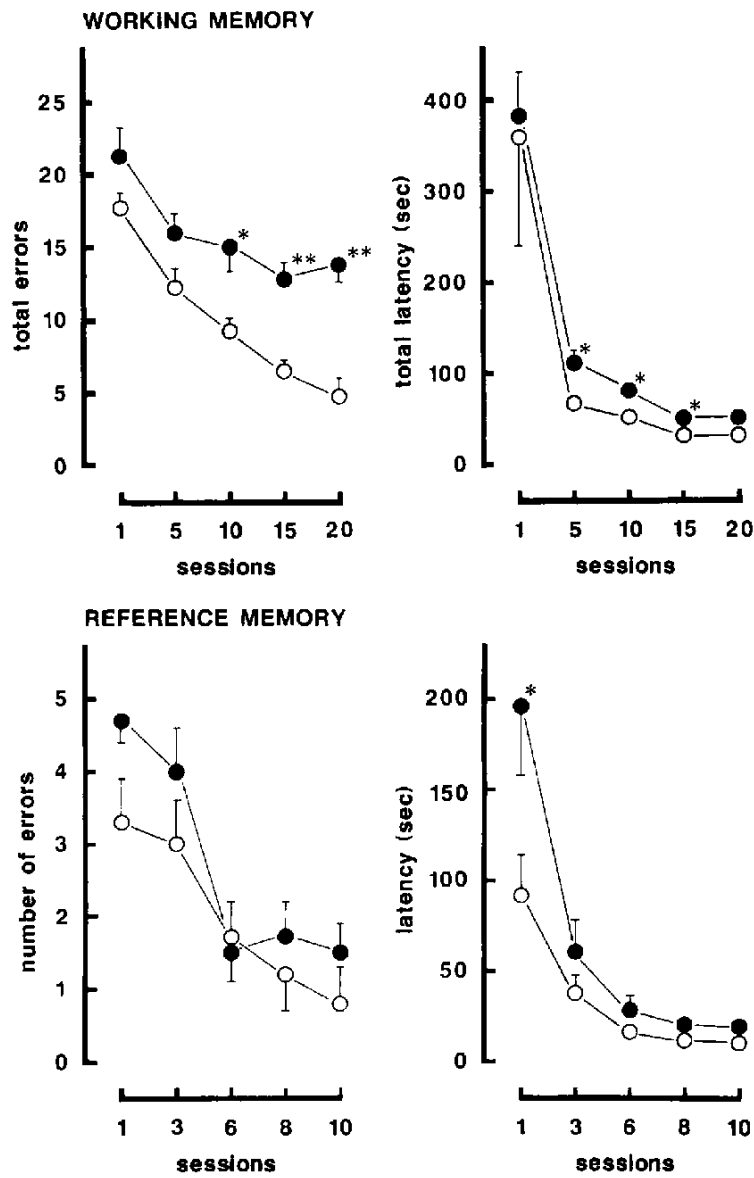

Fig. 2. Influences of dorsal hippocampal lesions on the acquisition of working and reference memory in the three-panel runway task. Initially, rats received hippocampal lesions and then given the runway training from the 6th day after surgery. Each point represents a mean $\pm S$.E. for six animals. In the working memory task (upper panels), the number of errors and latency summed from the second to sixth trial of a session were presented. Both items on the first trial of a session were presented in the reference memory task (lower panels). The significance of the differences from sham-lesioned rats was determined with the MannWhitney $U$-tcst. ${ }^{*} \mathrm{P}<0.05,{ }^{*}{ }^{*} \mathrm{P}<0.01 . \bigcirc$ : sham lesions, $O$ : hippocampal lesions. 
while errors in the first trial remained constant at approximately four. About 15-20 training sessions were required for the rats to achieve the criterion of less than 8 errors summed from the second to sixth trial of a session. In the dorsal hippocampal-lesioned rats, errors in the first trial were also maintained at approximately four throughout the sessions. The total number of errors in 2-6 trials made by the hippocampal-lesioned rats was significantly higher than that made by sham-lesioned rats in the 10 th and later training sessions. None of the six rats with hippocampal lesions reached the criterion of the working memory task after they were given 20 training sessions. Latency in 2-6 trials was significantly longer in the hippocampal-lesioned rats than in the shamlesioned rats from the 5th to 15 th session. However, the latency was markedly reduced in both groups as training sessions were repeated.

In the reference memory task, errors made by the dorsal hippocampal-lesioned rats decreased markedly with repetition of training, as seen in the sham-lesioned rats (Fig. 2, lower panels). Latency in both groups was similarly reduced with repeated sessions, while the latency in the first session in rats with hippocampal lesions was significantly longer than that in the sham-lesioned rats.

\section{Experiment 2}

Dorsal hippocampal lesions caused a marked increase in errors assessed by the working memory procedure in the three-panel runway task, without affecting the number of errors made in the first trial (Fig. 3 and Table 1). Latency in 2-6 trials was also significantly prolonged by hippocampal lesions. The number of working errors in hippocampal-lesioned rats did not decrease in the subsequent retraining sessions, and the values were significantly higher as compared with those seen in sham-lesioned rats until the 10th session (Fig. 4).

Physostigmine at $0.1 \mathrm{mg} / \mathrm{kg}$ and minaprine at $10 \mathrm{mg} / \mathrm{kg}$ significantly reduced the increase in working errors in rats with lesions of the dorsal hippocampus (Table 1). These drugs had no effect on prolonged latency in hippocampal lesioned rats. $S$-Adenosyl-L-methionine at $180 \mathrm{mg} / \mathrm{kg}$ failed to reduce the increase in working errors induced by hippocampal lesions. $S$-Adenosyl-L-methionine prolonged the latency in the first trial, as well as from the second to sixth trial.

In the reference memory task, neither the number of errors nor the latency was in-
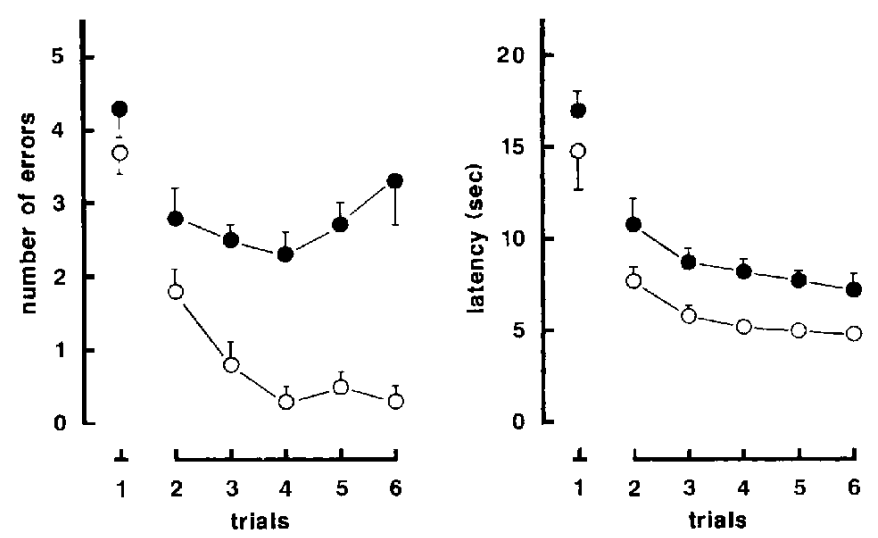

Fig. 3. Influence of dorsal hippocampal lesions on working memory in the three-panel runway task. Rats were trained preoperatively until they achieved the criterion and then subjected to hippocampal lesions. The runway test was held 5 days after surgery. Each point represents the mean $\pm \mathrm{S}$.E. of errors and latency for six animals on each trial of a session. $O$ : sham lesions, $O$; hippocampal lesions. 
Table 1. Effects of physostigmine, minaprine and $S$-adenosyl-i-methionine on impairment of working memory induced by dorsal hippocampal lesions in the three-panel runway task

\begin{tabular}{|c|c|c|c|c|c|c|c|}
\hline \multirow{2}{*}{ Treatment } & \multirow{2}{*}{ Drug } & \multirow{2}{*}{$\mathrm{mg} / \mathrm{kg}$} & \multirow{2}{*}{$\mathrm{N}$} & \multicolumn{2}{|c|}{ Number of errors } & \multicolumn{2}{|c|}{ Latency (sec) } \\
\hline & & & & Trial 1 & Trial $2-6$ & Trial 1 & Trial $2-6$ \\
\hline Sham lesions & - & - & 6 & $3.7 \pm 0.3$ & $3.8 \pm 0.6$ & $14.8 \pm 2.1$ & $28.5 \pm 2.3$ \\
\hline $\begin{array}{l}\text { Hippocampal } \\
\text { lesions }\end{array}$ & - & - & 6 & $4.3 \pm 0.4$ & $13.7 \pm 0.7^{\# \#}$ & $17.0 \pm 1.1$ & $42.5 \pm 3.3^{\#}$ \\
\hline $\begin{array}{l}\text { Hippocampal } \\
\text { lesions }\end{array}$ & Physostigmine & 0.1 & 6 & $4.0 \pm 0.5$ & $6.7 \pm 1.4^{* *}$ & $24.3 \pm 5.8$ & $61.0 \pm 10.9$ \\
\hline $\begin{array}{l}\text { Hippocampal } \\
\text { lesions }\end{array}$ & Minaprine & 10 & 6 & $2.8 \pm 0.4^{*}$ & $6.8 \pm 1.0^{* *}$ & $20.5 \pm 2.0$ & $43.7 \pm 5.8$ \\
\hline $\begin{array}{l}\text { Hippocampal } \\
\text { lesions }\end{array}$ & $\begin{array}{l}S \text {-Adenosyl- } \\
\text { L-methionine }\end{array}$ & 180 & 6 & $4.5 \pm 0.2$ & $12.5 \pm 1.3$ & $27.2 \pm 3.6^{*}$ & $83.3 \pm 18.7^{*}$ \\
\hline
\end{tabular}

Rats were trained preoperatively until they achieved the criterion and then subjected to hippocampal lesions. Physostigmine and minaprine were administered p.o. 1 hr before the runway test held 5 days after surgery. $S$-Adenosyl-L-methionine was injected i.p. $50 \mathrm{~min}$ before testing. Each value represents a mean \pm $\mathrm{S}$.E. The significance of the differences from sham-lesioned rats $\left({ }^{\#} \mathrm{P}<0.05,{ }^{\#} \mathrm{P}<0.01\right)$ and from hippocampal-lcsioned rats $\left({ }^{*} \mathrm{P}<0.05,{ }^{*} \mathrm{P}<0.01\right)$ was determined with the Mann-Whitney $U$-test.

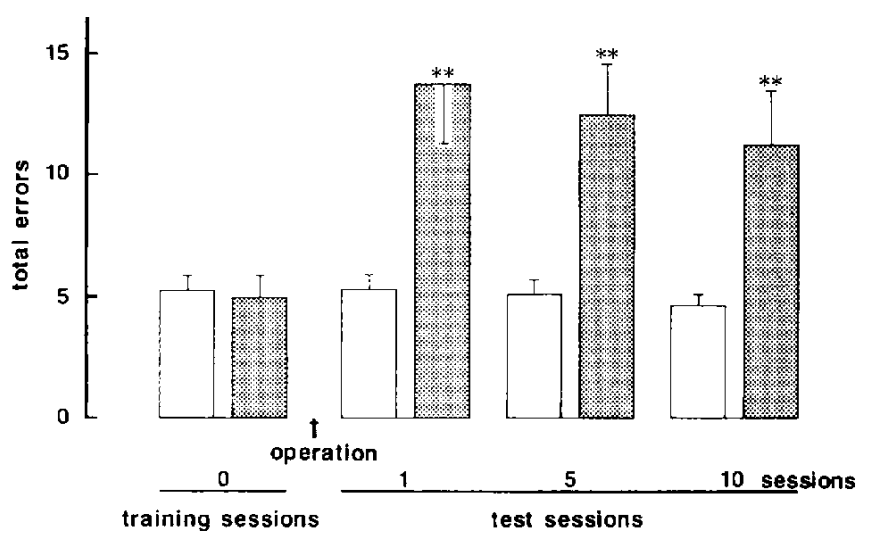

Fig. 4. Changes in the increase in working errors induced by dorsal hippocampal lesions when runway sessions were repeated. The rats had been retrained from the 5 th day after surgery. Each column represents the mean $\pm S$.E. of errors summed from the second to sixth trial of a session $(N=6)$. The significance of the differences from sham-lesioned rats was determined with the Mann-Whitney $U$-test. ${ }^{* *} \mathbf{P}<0.01$. $\square$ : sham lesions, : hippocampal lesions.

creased by dorsal hippocampal lesions (Table 2). In contrast, intraperitoneal injection of scopolamine at $0.56 \mathrm{mg} / \mathrm{kg}$ significantly in- creased both items in the reference memory task. 
Table 2. Influences of dorsal hippocampal lesions and scopolamine on the retention of reference memory in the three-panel runway task

\begin{tabular}{|c|c|c|c|}
\hline Treatment & $\mathbf{N}$ & Number of errors & Latency (sec) \\
\hline Sham lesions & 5 & $0.6 \pm 0.2$ & $12.5 \pm 1.5$ \\
\hline Hippocampal lesions & 6 & $1.3 \pm 0.4$ & $11.8 \pm 1.8$ \\
\hline Saline (i.p.) & 6 & $0.3 \pm 0.2$ & $11.0 \pm 1.9$ \\
\hline $\begin{array}{l}\text { Scopolamine } \\
0.56 \mathrm{mg} / \mathrm{kg} \text { (i.p.) }\end{array}$ & 6 & $4.3 \pm 0.5^{* *}$ & $92.4 \pm 8.9^{* *}$ \\
\hline
\end{tabular}

The runway test was held 5 days after hippocampal lesions or $20 \mathrm{~min}$ after injection of scopolamine. Each value is the mean \pm S.E. of errors and latency on the first trial of a session. The significance of the differences from sham-lesioned or saline-injected rats was determined with the Mann-Whitney $U$-test. ${ }^{*} * \mathbf{P}<0.01$.

\section{DISCUSSION}

Working memory allows animals to remember information that is useful for a single session of an experiment but not for subsequent sessions, whereas reference memory is defined as the holding of information that is of continued value across all sessions $(15,16)$. In the present study, lesions of the dorsal hippocampus significantly impaired acquisition of working memory, without affecting the acquisition of reference memory in a three-panel runway task. In addition, rats trained preoperatively and then subjected to hippocampal lesions exhibited a marked impairment of working memory, while they had normal retention of reference memory. Jarrard (17) and Olton and Papas (18) have reported that hippocampal lcsions produce deficits in working memory, but do not have much influence on reference memory in the radial maze with only half of the arms baited. Similar results were obtained in rats with hippocampal neuronal damage induced by transient forebrain ischemia $(19,20)$. These findings demonstrate that the hippocampus is selectively involved in working memory, but not in reference memory. Consistently, humans with hippocampal lesions can not remember new information that occurs in their daily lives, while they can communicate normally at least about events that occurred before their brain damage developed
$(4,5)$. The working memory impairment in rats with hippocampal lesions did not recover from levels observed at the first postoperative test even if 10 re-training sessions were given postoperatively once each day. It has also been reported that rats with destruction of the septum or fimbria-fornix anterior to the hippocampus had marked impairment of working memory performance in the radial maze and showed no signs of recovery of function when they were given 50 postoperative retraining sessions $(1,2)$. Thus, a functional hippocampal system is necessary for normal performance in the working memory task.

Central cholinergic function has been suggested to play an important role in learning and memory. The administration of scopolamine, a muscarinic acetylcholine receptor antagonist, produces amnesic effects $(21-23)$, while cholinergic drugs, including muscarinic agonists and acetylcholinesterase inhibitors, accelerate learning and memory in both humans and animals $(22,24,25)$. The most striking and consistent change in AD and SDAT is in the cholinergic system, as measured by a marked decrease in choline acetyltransferase activity in the hippocampus and cerebral cortex $(8,9)$. These findings have drawn attention to the cholinergic system as a possible site for therapy of the dementing disorders. Recently, Summers et al. (26) reported improvements in SDAT patients following administra- 
tion of a potent cholinesterase inhibitor, tetrahydroaminoacridine. The present study clearly indicated that physostigmine, a wellknown cholinesterase inhibitor, exerted an ameliorating effect on the impairment of working memory induced by dorsal hippocampal lesions in the three-panel runway task. Minaprine also improved the deficit of working memory in hippocampal-lesioned rats. Minaprine was shown to increase the release of $\mathrm{ACh}$ from the hippocampus, by blocking the presynaptic $5-\mathrm{HT}_{2}$ receptor on the cholinergic neuron (27). Both physostigmine and minaprine reverse the memory impairment induced by scopolamine in this task (11). On the other hand, the methyl donor $S$-adenosyl-Lmethionine, which exerts an amcliorating effect on working memory impairment induced by cerebral ischemia in this task (14). failed to improve the impaired working memory in rats with hippocampal lesions. We have previously reported that $S$-adenosyl-L-methionine also does not attenuate the scopolamineinduced impairment of runway performance in rats (14). These results, along with the wellknown septo-hippocampal acetylcholine fibers $(28,29)$, suggest that lowering of the cholinergic function contributes to the impairment of working memory following hippocampal lcsions in the three-panel runway task. This is consistent with the fact that injections of scopolamine into the dorsal hippocampus deteriorate the working memory of rats as assessed by a $T$-maze alternation task (30).

Reference memory was not influenced by hippocampal lesions, while it was markedly impaired by intraperitoneal injection of scopolamine. Systemic scopolamine also deteriorates working memory in the three-panel runway task $(10,11)$. Okaichi et al. (31) reported that scopolamine impairs not only the working memory but also the reference memory of rats in the eight-arm radial maze with 4 arms baited. Intrahippocampal injections of scopolamine impair the performance of working memory tasks to a greater extent than they affect reference memory tasks (30). Therefore, it is conceivable that the septo-hippocampal cholinergic system does not play a role in reference memory, unlike its contribution to working memory, and that systcmic injection of scopolamine impairs reference memory through its blocking action on muscarinic receptors in brain regions other than the hippocampus.

We conclude that lesions of the dorsal hippocampus in rats lead to the selective impairment of working memory, which is attributable to a lowering of the cholinergic function.

\section{Acknowledgements}

We wish to thank Taisho Pharmaceutical Co., Ltd. (Ohmiya, Japan) and Fuji Chemical Industry Co., Ltd. (Toyama, Japan) for providing the generous supplies of minaprine and $S$-adenosyl-t-methionine, respectively. This research was supported in part by a Grant-in-Aid for Scientific Research from the Ministry of Education, Science and Culture of Japan.

\section{REFERENCES}

1 Becker, J.T., Walker, J.A. and Olton, D.S.: Neuroanatomical bases of spatial memory. Brain Res. 200, 307-320 (1980)

2 Olton, D.S., Walker, J.A. and Gage, F.H.: Hippocampal connections and spatial discrimination. Brain Res. 139, 295 - 308 (1978)

3 Morris, R.G.M., Garrud, P., Rawlins, J.N.P. and O'Keefe, $\mathbf{J}$.: Place navigation impaired in rats with hippocampal lesions. Nature 297, 681-683 (1982)

4 Corkin. S.: Lasting consequences of bilateral medial temporal lobectomy: Clinical course and experimental findings in H.M. Semin. Neurol. 4, 249 -259 (1984)

5 Zola-Morgan, S., Squire, L.R. and Amaral, D.G.: Human amnesia and the medial temporal region: Enduring memory impairment following a bilateral lesion limited to field CA1 of the hippocampus. $J$. Neurosci. 6, 2950-2967 (1986)

6 Ball, M.J.: Neuronal loss, neurofibrillary tangles and granulovacuolar degeneration in the hippocampus with aging and dementia: A quantitative study. Acta Neuropathol. (Berl.) 37, 111-118 (1982)

7 Hyman, B.T., Van Hoesen, G.W., Damasio, A.R. and Barnes, C.L.: Alzheimer's disease: Cellspecific pathology isolates the hippocampal formation. Science 225, $1168-1170$ (1984)

8 Davies, P. and Maloney, A.J.F.: Selective loss of central cholinergic neurons in Alzheimer's disease. Lancet 2, 1403 (1976) 
9 Henke, H. and Lang, W.: Cholinergic enzymes in neocortex, hippocampus and basal forebrain of non-neurological and senile dementia of Alzheimertype patients. Brain Res. 267, $281-291$ (1983)

10 Furuya, Y., Yamamoto, T., Yatsugi, S. and Ueki, S.: A new method for studying working memory by using the three-panel runway apparatus in rats. Japan. J. Pharmacol. 46, 183-188 (1988)

11 Yamamoto, T., Yatsugi, S., Ohno, M., Furuya. Y., Kitajima, I. and Ueki, S.: Minaprine improves impairment of working memory induced by scopolamine and cerebral ischemia in rats. Psychopharmacology (Berlin) 100, 316-322 (1990)

12 Paxinos, $G$. and Watson, $C$.: The Rat Brain in Stereotaxic Coordinates. Academic Press, New York (1982)

13 Yamamoto, T., Ohno, M., Kitajima, I. and Ueki, S.: Effects of nootropic drugs on experimentally induced amnesia of rats in the three-pancl runway task. In Basic, Clinical, and Therapeutic Aspects of Alzheimer's and Parkinson's Diseases, Vol. 2. Edited by Nagatsu, T., Fisher, A. and Yoshida. M., p. 439-443, Plenum Press, New York (1990)

14 Yatsugi, S., Yamamoto, T., Ohno, M. and Ueki, $S$.: Effect of $S$-adenosyl-L-methionine on impairment of working memory induced in rats by cerebral ischemia and scopolamine. Eur. J. Pharmacol. 166, 231 - 239 (1989)

15 Honig, W.K.: Studies of working memory in the pigeon. In Cognitive Aspects in Animal Behavior, Edited by Hulse, S.H., Fowler, H. and Honig, W.K., p. 211-248, Lawrence Erlbaum, Hillsdale (1978)

16 Olton, D.S., Becker, J.T. and Handelmann, G.E.: Hippocampus, space, and memory. Behav. Brain Sci. 2, 313-365 (1979)

17 Jarrard, L.E.: Selective hippocampal Iesions and behavior. Physiol. Psychol. 8, 198-206 (1980)

18 Olton, D.S. and Papas, B.C.: Spatial memory and hippocampal function. Neuropsychologia 17, 669$682(1979)$

19 Davis, H.P., Baranowski, J.R., Pulsinelli, W.A. and Volpe, B.T.: Retention of reference memory following ischemic hippocampal damage. Physiol. Behav. 39, $783-786$ (1987)

20 Davis, H.P., Tribuna, I., Pulsinelli, W.A. and Volpe, B.T.: Reference and working memory of rats following hippocampal damage induced by transient forebrain ischemia. Physiol. Behav. 37.
$387-392(1986)$

21 Frumier, M.J., Herckar, V.R. and Jarvik, M.E: Amnesic actions of diazepam and scopolamine in man. Anesthesiology 45, 406-410 (1976)

22 Sitaram, N., Weingartner, H. and Gillin, J.C.: Human serial learning: Enhancement with arecholine and choline and impairment with scopolamine. Science 201, 274-276 (1978)

23 Watts, J., Stevens, R. and Robinson, C.: Effects of scopolamine on radial maze performance in rats. Physiol. Behav. 26, 845-851 (1981)

24 Davis, K.L., Mohs, R.C., Tinklenberg, J.R., Pfefferbaum, A., Hollister, L.E. and Koppel, B.S.: Physostigmine: Improvement of long-term memory processes in normal humans. Science 201, 272274 (1978)

25 Baratti, C.M., Huygens, P., Min̄o, J., Mcrlo, A. and Gardella, J.: Memory facilitation with posttrial injection of oxotremorine and physostigmine in mice. Psychopharmacology (Berlin) 64, 85-88 (1979)

26 Summers, W.K., Majovski, L.V., Marsh, G.M., Tachiki, K. and Kling, A.: Oral tetrahydroaminoacridine in long-term treatment of senile dementia, Alzheimer type. N. Engl. J. Med. 315, 12411245 (1986)

27 Muramatsu, M., Tamaki-Ohasi, J., Usuki, C., Araki, H. and Aihara, H.: Serotonin-2 receptormediated regulation of release of acetylcholine by minaprine in cholinergic nerve terminal of hippocampus of rat. Neuropharmacology 27, 603-609 (1988)

28 Mellgren, S.I. and Srebro, B.: Changes in acetylcholinesterase and distribution of degenerating fibres in the hippocampal region after septal lesions in the rat. Brain Res. 52, 19-36 (1973)

29 Meibach, R.C. and Siegel, A.: Efferent connections of the septal area in the rat: An analysis utilizing retrograde and anterograde transport methods. Brain Res. 119, 1 -20 (1977)

30 Brito, G.N.O., Davis, B.J., Stopp, L.C. and Stanton, M.E.: Memory and the septo-hippocampal cholinergic system in the rat. Psychopharmacology (Berlin) 81, 315-320 (1983)

31 Okaichi, H., Oshima, Y. and Jarrard, L.E.: Scopolamine impairs both working and reference memory in rats: A replication and extension. Pharmacol. Biochem. Behav. 34, 599-602 (1989) 